\title{
Studies of Bilirubin Kinetics in Normal Adults
}

\author{
Paul D. Berk, Robert B. Howe, Joseph R. Bloomer, and \\ Nathaniel I. BerLin \\ From the Metabolism Branch, National Cancer Institute, National Institutes of \\ Health, Bethesda, Maryland 20014
}

A B S T RACT This report describes studies of bilirubin kinetics in 13 healthy young adults. The plasma content of unconjugated bilirubin $-{ }^{14} \mathrm{C}$ was determined at frequent intervals for 24-30 hr after the intravenous injection of a tracer dose of unconjugated isotopic bilirubin. Fecal and urinary radioactivity were measured for 7 days. During this time cumulative recovery averaged $96 \%$ of the injected dose. The plasma curves were processed by digital computer. For the $30 \mathrm{hr}$ experimental period, a sum of three exponentials, with average half-times of 18,81 , and $578 \mathrm{~min}$, was required to describe the data. Using the plasma curve integral method, the hepatic bilirubin clearance $(47 \pm 10 \mathrm{ml} / \mathrm{min}$, mean $\pm \mathrm{SD})$, the bilirubin production rate $(3.8 \pm 0.6 \mathrm{mg} / \mathrm{kg}$ per day), and the mean red blood cell life span (101 \pm 13 days) were calculated directly from the parameters of this function. To gain further insight into the metabolism of unconjugated bilirubin, the data were also used to determine the parameters of a multicompartmental model. In the model proposed, plasma unconjugated bilirubin exchanges with two additional pools, one of which is thought to represent extrahepatic extravascular, and the other intrahepatic unconjugated bilirubin. Bilirubin is eliminated from the system via the proposed intrahepatic pool. From the data and the model, pool sizes and exchange rates between compartments were calculated, and the liver : plasma concentration gradient estimated. These studies provide a detailed analysis of the kinetics of unconjugated bilirubin in a healthy normal population and are intended to serve as a reference point for studies of abnormal states.

\section{INTRODUCTION}

After the biosynthesis of bilirubin $-{ }^{14} \mathrm{C}$ by Ostrow, Hammaker, and Schmid in 1961 (1), this material was used to determine the plasma clearance patterns and bilirubin turnover rates in children with Crigler-Najjar syn-

Received for publication 13 March 1969 and in revised form 1 June 1969. drome (2-4) and congenital biliary atresia (5). In these unique situations, the existence of a very large whole body bilirubin pool with a slow turnover rate permitted the use of labeled bilirubin of low specific activity, and of relatively simple methods of data analysis. The development of methods for producing bilirubin $-{ }^{14} \mathrm{C}$ of greater specific activity $(6,7)$, of a simple method for the quantitative separation of unconjugated from conjugated plasma bilirubin (8), and of alternative mathematical methods for processing more complex kinetic data (9) have made it possible to carry out such studies in any clinical situation. Our initial report demonstrated the presence of characteristically abnormal clearance patterns of bilirubin ${ }^{14} \mathrm{C}$ in certain disease states, and of increased rates of bilirubin turnover in association with hemolysis or increased ineffective erythropoiesis (10). Further investigation has confirmed the value of isotopic bilirubin clearance studies in the clinical assessment of hepatic function and in the measurement of red blood cell life span $(11,12)$. This report describes studies of bilirubin kinetics in 13 young, healthy adults. Data were processed by digital computer and used to calculate the hepatic bilirubin clearance, the bilirubin production rate, the mean red blood cell life span, and the parameters of a multicompartmental model of the metabolism of unconjugated bilirubin. These studies provide a detailed description of the kinetics of unconjugated bilirubin in normal man and are intended to serve as a reference point for studies of abnormal states.

\section{METHODS}

Subjects. Seven male and five female normal volunteers, age 21-24 yr, were included in these studies. Each was admitted to the National Institutes of Health for a minimum of 6 wk, between May, 1967 and August, 1968. Volunteers met the following requirements: no history of jaundice, acute or chronic liver disease, or infectious mononucleosis; no history of anemia; no dietary abnormalities, alcohol, or drug ingestion; normal values for the following laboratory investigations: hemoglobin, hematocrit, white blood count, platelet count, reticulocyte count (average $<1 \%$ with no value $>1.5 \%)$, chromium-labeled red cell survival $\left(T_{1}>26\right.$ 
days); bilirubin concentration and partition, serum glutamic oxaloacetic transaminase (SGOT), alkaline phosphatase, serum albumin concentration $(>4.0 \mathrm{~g} / 100 \mathrm{ml})$ and protein electrophoresis, sulfobromophthalein (BSP) retention $(<5 \%$ of $5 \mathrm{mg} / \mathrm{kg}$ dose at $45 \mathrm{~min}$ ), fecal and urine urobilinogen excretion, chest X-ray, electrocardiogram, and urinalysis. Liver biopsy was not done. One additional subject, (J. L.), a $19 \mathrm{yr}$ old male, was admitted to the Metabolism Branch of the National Cancer Institute from September, 1967 to June, 1968 for management of exogenous obesity. By means of an exercise program and dietary restriction to no fewer than 1100 calories, weight loss from 320 to $180 \mathrm{lb}$. was achieved. This subject met the above criteria in all other respects. Bilirubin kinetic studies in January and May, 1968, when he weighed 248 and 194 pounds, were indistinguishable from those of the volunteers, and he was, therefore, included in the study.

Preparation of isotopic bilirubin. Bilirubin $-{ }^{14} \mathrm{C}$ was prepared biosynthetically in bile fistula dogs from $\delta$-aminolevulinic acid-4- ${ }^{14} \mathrm{C}$ (ALA $-4-{ }^{14} \mathrm{C}$ ), and purified to constant specific activity and a molar extinction coefficient of $58,000-61,000$ (7). Aliquots containing $350-500 \mu \mathrm{g}$ of bilirubin were placed in individual dosage vials. Specific activity of various lots differed, so that each dose contained $0.6-3.7 \mu \mathrm{c}$ of bilirubin${ }^{14} \mathrm{C}$. The vials were stored in vacuo, in the dark, at $-20^{\circ} \mathrm{C}$ until needed. The storage period never exceeded 4 months. Studies in our laboratory have indicated stability of bilirubin- ${ }^{14} \mathrm{C}$ under these conditions for periods in excess of 6 months with no significant change in molar extinction coefficient.

Plasma bilirubin- ${ }^{14} \mathrm{C}$ clearance studies. Bilirubin- $-{ }^{14} \mathrm{C}$ clearance studies were carried out using the method of Barrett, Berk, Menken, and Berlin (10). In this procedure, the plasma content of unconjugated bilirubin- ${ }^{14} \mathrm{C}$ is determined by extraction of unconjugated bilirubin from plasma samples into the nonpolar layer of a two phase solvent system according to the method of Weber and Schalm (8). An aliquot of the lower layer is then counted in a liquid scintillation spectrometer. The following changes were introduced in the previously described protocol: (a) The volume of albumin used to prepare each dose for injection was increased to $11.5 \mathrm{ml}$ to improve buffering. For each study, $10.0 \mathrm{ml}$ of bilirubin- ${ }^{14} \mathrm{C}$-albumin were injected intravenously. (b) The period of sampling was extended to $24-30 \mathrm{hr}$. (c) Before the addition of counting solution to each sample, samples were bleached by exposure to ultraviolet light for $24-48 \mathrm{hr}$. This procedure did not result in any loss of isotope, but did significantly reduce quenching and improve counting efficiency. ( $d$ ) Because the count rate in the late samples (after $18 \mathrm{hr}$ ) was only 1.5-2.0 times background, each study was counted repeatedly before the addition of internal standard until a minimum of 10,000 counts was collected on all samples including backgrounds. This was sufficient to insure an error of $<3.6 \%$ in the net count rate of the least active samples. The error in net count rate for samples collected during the first $9 \mathrm{hr}$ after injection was $<1 \%$. An average of 8 days of continuous counting was required for each study in order to achieve the desired statistical precision. (e) The partition coefficient (P) (fraction of plasma unconjugated bilirubin extracted into the lower layer) of the Weber-Schalm solvent system was determined for each study as follows. A $50 \mu \mathrm{l}$ aliquot of the injected bilirubin $-{ }^{14} \mathrm{C}-$ albumin mixture was added to $5 \mathrm{ml}$ of the patient's unlabeled plasma. This sample was extracted by the same method as the experimental plasma samples, and the radioactivity recovered in the lower (nonpolar) layer compared with that found in $50 \mu \mathrm{l}$ aliquots of the same material added directly to counting vials without extraction.

During each study, at least 10 measurements of plasma unconjugated bilirubin concentration were made, using the method of Weber and Schalm (8). No systematic changes were observed with time. Therefore, the mean plasma unconjugated bilirubin concentration $(\overline{\mathrm{BR}})$ was used for calculation of the plasma bilirubin pool (see below).

Fecal and urine radioactivity. Feces and urine were collected in 24-hr blocks for 7 days after injection of bilirubin${ }^{14} \mathrm{C}$. The total carbon-14 content of each $24-\mathrm{hr}$ stool collection was determined as described by Crigler and Gold (4), using an oxygen flask combustion method (13). No attempt was made to crystallize bilirubin $-{ }^{14} \mathrm{C}$ or stercobilin $-{ }^{14} \mathrm{C}$ from the feces. After 10-fold concentration by lyophilization, the urine $-{ }^{14} \mathrm{C}$ content was determined as previously described (4).

Red cell volume and ${ }^{51} \mathrm{Cr}$ half-life. The ${ }^{51} \mathrm{Cr}$ method of Sterling and Gray (14) as modified by Read (15) was used to measure the total red cell volume and the $\mathrm{T}_{1}$ of ${ }^{51} \mathrm{Cr}$-labeled red cells. Plasma volume (PV) was calculated from the total red cell volume and the peripheral venous hematocrit $(\mathrm{VH})$. Based on studies of the relationship of $\mathrm{VH}$ to the whole body hematocrit $(\mathrm{BH})$, we calculated an "estimated albumin distribution space" equal to $\mathrm{PV} \times(\mathrm{VH} / \mathrm{BH}) \times(1-$ $\mathrm{BH}) /(1-\mathrm{VH})$ for each study, assuming that the average ratio of whole body hematocrit to venous hematocrit was $0.91(16-18)$.

Six subjects were studied twice, at intervals of $1-10$ months, to determine the reproducibility of the bilirubin $-{ }^{14} \mathrm{C}$ clearance study. Blood volume was measured with each bilirubin clearance study, but in only one instance (subject D. R.), when the interval between studies was 10 months, was the ${ }^{51} \mathrm{Cr}$ red cell survival redetermined.

Data analysis. Data processing was done on a Univac 1108 digital computer, using the Simulation, Analysis and Modeling (SAAM) program of Berman and Weiss. Notation is consistent with the SAAM manual (19). The program uses an iterative nonlinear least squares fitting procedure to determine the parameters of a mathematical curve describing the data, or the parameters of a compatible model. In the region of the least squares solution, the computer also generates a variance-covariance matrix for these parameters, from which it calculates their uncertainties, as well as their correlation coefficients. Details of the program and of the data fitting techniques embodied in it have been previously published (19-22).

The plasma bilirubin $-{ }^{14} \mathrm{C}$ clearance data for each study (expressed as fraction of dose per milliliter of plasma) were fitted to sums of two three, and four exponential functions. The function used took the form:

$$
q(t)=K\left(\sum_{j=1}^{n} A_{1 j} e^{-\alpha_{j} t}\right), n=2,3,4
$$

where $\sum_{j=1}^{n} A_{1 j}=1$. Using previously described criteria

$(10,20)$, it was found that three exponentials were both necessary and sufficient to describe the data when sampling was carried out over an experimental period of 24-30 hr. By means of the plasma curve integral method (23) $k_{e}$, the fraction of the plasma unconjugated bilirubin pool irreversibly cleared per minute by the liver, was calculated as follows :

$$
\mathrm{k}_{\mathrm{e}}=\left(\sum_{j=1}^{3} \frac{\mathrm{A}_{\mathrm{i}_{j}}}{\alpha_{\mathrm{j}}}\right)^{-1}
$$




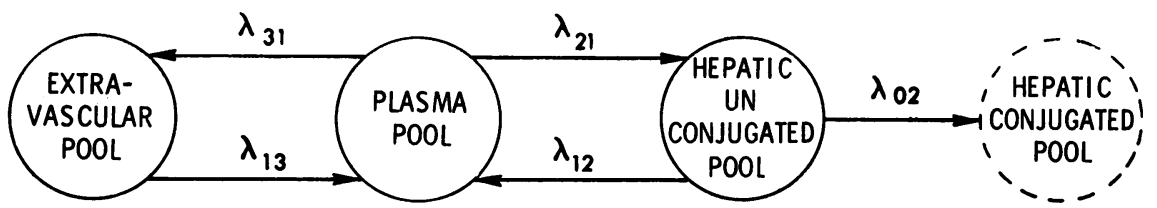

Figure 1 A three compartment model of the metabolism of unconjugated bilirubin. Values for the $\lambda^{\prime}$ 's, which are the fractional transfer rates between compartments, and for the pool sizes are calculated from the plasma disappearance curve of unconjugated bilirubin $-{ }^{14} \mathrm{C}$ and the concentration of unconjugated bilirubin in the plasma.

The following physiologic parameters were also calculated from the parameters of the three exponential functions and the mean plasma concentration of unconjugated bilirubin $(\overline{\mathrm{BR}})$, as previously described (10): (a) VDBR, the initial distribution volume of injected bilirubin $-{ }^{14} \mathrm{C} ;(b) \mathrm{M}_{1}$, the mass of the rapidly mixing (plasma) pool ; $(c)$ the efficiency of bilirubin extraction by the liver; and $(d)$ BRP, the bilirubin production rate. The volume of plasma cleared of bilirubin each minute $\left(C_{B R}\right)$ was calculated according to the equation:

$$
\mathrm{C}_{\mathrm{BR}}=\frac{\mathrm{k}_{\mathrm{e}} \times \mathrm{M}_{1}}{\overline{\mathrm{BR}}}=\mathrm{k}_{\mathrm{e}} \times \mathrm{VDBR} .
$$

The mean red blood cell life span (RBCLS) was estimated from $\mathrm{BRP}$ and the total red cell volume, assuming a $15 \%$ contribution to BRP from sources other than senescent red blood cells (24). Calculations of $M_{1}, k_{e}$, efficiency, $C_{B R}$, and RBCLS are independent of assumptions about the compartmental arrangement of the exchanging bilirubin system (9, 23).

In an attempt to gain further insight into the metabolism of unconjugated bilirubin, it was next assumed that the system involved is compartmentalized. The presence of three exponentials in the plasma bilirubin $-{ }^{14} \mathrm{C}$ clearance function indicates the existence of two kinetically distinct pools exchanging with plasma $(25,26)$. Accordingly, in the model selected (Fig. 1), plasma unconjugated bilirubin (compartment 1) is considered to exchange with an extravascular pool (compartment 3) and a hepatic pool (compartment 2) of unconjugated bilirubin. Unconjugated bilirubin is assumed to be eliminated from the system solely from compartment 2 , presumably by conjugation. Alternate minor pathways of bilirubin elimination were not considered.

The following notation was used: The mass of bilirubin in the $i^{\text {th }}$ compartment is indicated by $M_{1}$; the fraction of compartment $i$ transferred to compartment $j$ per minute by the constant $\lambda_{11}$; and the fraction of the $i^{\text {th }}$ pool eliminated from the system per minute by $\lambda_{01}$. $R_{11}$, the mass of bilirubin transferred per minute from compartment $i$ to compartment $j$ is therefore, equal to $\lambda_{j 1} \mathrm{M}_{1}$. A steady state was assumed, so that all $M_{1}$ are considered to be constant. The fractional turnover rate of the $i^{\text {th }}$ pool, $\lambda_{11}$, is the sum of all fractional transfer rates out of the pool. Thus,

$$
\lambda_{i i}=\sum_{j=0}^{3} \lambda_{j i} \text { for } j \neq i .
$$

Note that some of these transfer rates are implicitly considered to be zero (see Fig. 1).

If the isotope content (fraction of dose) of the $i^{\text {th }}$ compartment is denoted by $f_{i}$, then the transfer of unconju- gated bilirubin- $-{ }^{14} \mathrm{C}$ between the compartments of the model can be described by a set of three linear differential equations of the form:

$$
\frac{d f_{i}}{d t}=-\lambda_{i i} f_{i}+\sum \lambda_{i j} f_{j}, \quad \text { for } i=1,2,3 \text {, and } j \neq i \text {. }
$$

It can readily be shown by the use of Laplace transforms (27) that, for $i=1,2,3$,

$$
f_{i}(t)=A_{i 1} e^{-\alpha_{1} t}+A_{i 2} e^{-\alpha_{2} t}+A_{i 3} e^{-\alpha_{3} t} .
$$

Comparing equations 1 and 5 , it is apparent that the solution obtained for compartment 1 of the model is proportional to the experimentally determined plasma bilirubin $-{ }^{14} \mathrm{C}$ disappearance curve $q(t)$ :

$$
f_{1}(t)=q(t) / K \text {, }
$$

and that $\mathrm{K}=1 / \mathrm{VDBR}$. It has previously been shown that a solution may be obtained for five parameters of a 3 compartment model, (e.g. $\lambda_{21}, \lambda_{12}, \lambda_{02}, \lambda_{31}, \lambda_{13}$ ), as well as the independent coefficients of $f_{2}(t)$ and $f_{3}(t)$, if the coefficients and rate constants of the plasma curve $f_{1}(t)$ are known (28). Accordingly, from the experimental data, the solutions of equation 4 , and the steady-state conditions (27), values for the following parameters of physiologic interest can be obtained: $(a) \mathrm{M}_{1}, \mathrm{M}_{2}$, and $\mathrm{M}_{3}$, the sizes of the plasma, hepatic, and extravascular pools of unconjugated bilirubin; $(b)$ the fractional transfer rates $\left(\lambda_{11}\right)$ between compartments; $(c)$ $\mathrm{k}_{\mathrm{e}}, \mathrm{C}_{\mathrm{BR}}$, and the efficiency of hepatic bilirubin extraction; (d) $\mathrm{R}_{21}$, the rate of hepatic bilirubin uptake; (e) $\mathrm{MCBR}_{\mathrm{L}}{ }^{1}$ and MCR, ${ }^{1}$ estimates of the intrahepatic bilirubin concentration and the liver: plasma concentration gradient; $(f)$ BRP; and $(g)$ RBCLS. In addition, the model was used for computer calculation of the cumulative fraction of injected bilirubin ${ }^{11} \mathrm{C}$ conjugated, as well as the isotope content of the hepatic and extravascular pools, at various times after injection. Because the plasma curve integral method and compartmental analysis are equivalent mathematically (26), values of $M_{1}, k_{e}, C_{B R}$, efficiency, $B R P$, and RBCLS calculated from the model are identical to those calculated directly from the parameters of the plasma bilirubin $-{ }^{14} \mathrm{C}$ clearance curve.

In all individuals studied twice, differences in the plasma bilirubin ${ }^{14} \mathrm{C}$ clearance curves were observed between the first and second studies. The values and uncertainties in the $\lambda_{j 1}$ obtained for each pair of studies were examined graphically and by computer to determine whether the changes in the curves could be attributed to a consistent pattern of changes in these parameters.

\footnotetext{
${ }^{1}$ Calculated as previously described (10), except that the hepatic volume was estimated as equal to $2 \%$ of body weight.
} 
TABLE I

Preliminary Laboratory Data in Thirteen Healthy Young Adults

\begin{tabular}{|c|c|c|c|c|c|c|c|c|c|}
\hline \multirow[b]{2}{*}{ Subject } & \multirow[b]{2}{*}{ Sex } & \multirow[b]{2}{*}{ Age } & \multirow[b]{2}{*}{ Weight } & \multirow{2}{*}{$\begin{array}{l}\text { Red cell* } \\
\text { volume }\end{array}$} & \multirow{2}{*}{$\begin{array}{l}\text { Plasma* } \\
\text { volume }\end{array}$} & \multirow[b]{2}{*}{ RBC-T $*$ * } & \multirow{2}{*}{$\begin{array}{l}45 \mathrm{~min} \\
\text { BSP re- } \\
\text { tention } \ddagger\end{array}$} & \multicolumn{2}{|c|}{$\begin{array}{l}\text { Plasma bilirubin con- } \\
\text { centrationई }\end{array}$} \\
\hline & & & & & & & & Conjugated & Unconjugated \\
\hline & & $y r$ & $\mathrm{~kg}$ & $m l / k g$ & $m l / k g$ & days & $\%$ & \multicolumn{2}{|c|}{$\mathrm{mg} / 100 \mathrm{ml}$} \\
\hline L. H. & $\mathbf{M}$ & 23 & 80.1 & 28.5 & 36.3 & 26.7 & 3.0 & $0.15 \pm 0.03$ & $0.29 \pm 0.02$ \\
\hline D. R. (1)\| & $\mathbf{M}$ & 21 & 83.5 & 29.1 & 40.9 & 31.2 & 4.0 & $0.04 \pm 0.02$ & $0.44 \pm 0.04$ \\
\hline D. R. (2) & & 22 & 84.2 & 30.4 & 43.4 & 32.1 & 3.0 & $0.07 \pm 0.01$ & $0.43 \pm 0.05$ \\
\hline M. B. & $\mathbf{M}$ & 21 & 68.5 & 24.3 & 28.5 & $(106) \rrbracket$ & 2.0 & $0.00 \pm 0.00$ & $0.30 \pm 0.01$ \\
\hline N. H. & $\mathbf{M}$ & 22 & 75.4 & 30.4 & 38.7 & 27.3 & 3.0 & $0.10 \pm 0.01$ & $0.42 \pm 0.05$ \\
\hline R. G. & $\mathbf{M}$ & 22 & 60.0 & 37.5 & 38.6 & 30.8 & - & $0.06 \pm 0.01$ & $0.48 \pm 0.02$ \\
\hline D. K. & $\mathbf{M}$ & 22 & 72.2 & 28.0 & 39.0 & 28.2 & 2.0 & $0.12 \pm 0.02$ & $0.45 \pm 0.06$ \\
\hline J. L. (1)\| & $\mathbf{M}$ & 19 & 112.7 & 22.1 & 33.0 & 31.3 & - & $0.13 \pm 0.01$ & $0.48 \pm 0.03$ \\
\hline J. L. (2) & & & 88.3 & 26.8 & 39.4 & - & 4.0 & $0.15 \pm 0.01$ & $0.54 \pm 0.04$ \\
\hline G. M. (1)\| & $\mathbf{M}$ & 21 & 68.5 & 27.2 & 31.3 & 27.3 & 2.0 & $0.11 \pm 0.01$ & $0.52 \pm 0.04$ \\
\hline G. M. (2) & & & 69.1 & 31.2 & 37.3 & 一 & 一 & $0.04 \pm 0.01$ & $0.47 \pm 0.06$ \\
\hline Mean & & & & 28.7 & 36.9 & 29.4 & 2.9 & 0.09 & 0.44 \\
\hline$\pm \mathrm{SD}$ & & & & 3.8 & 4.2 & 2.1 & 0.8 & 0.05 & 0.08 \\
\hline M. K. & $\mathrm{F}$ & 23 & 42.2 & 27.3 & 47.0 & 36.8 & 2.0 & $0.01 \pm 0.01$ & $0.34 \pm 0.04$ \\
\hline L. B. & $\mathrm{F}$ & 24 & 62.5 & 20.1 & 36.4 & (129) & 3.0 & $0.05 \pm 0.01$ & $0.44 \pm 0.04$ \\
\hline S. B. (1)\| & $\mathrm{F}$ & 24 & 59.7 & 24.8 & 36.6 & 27.1 & 4.5 & $0.07 \pm 0.01$ & $0.52 \pm 0.04$ \\
\hline S. B. (2) & & & 57.2 & 26.8 & 37.7 & - & - & $0.07 \pm 0.01$ & $0.39 \pm 0.03$ \\
\hline C. K. (1)\| & $\mathrm{F}$ & 21 & 62.2 & 25.9 & 43.5 & 29.7 & 2.0 & $0.04 \pm 0.01$ & $0.34 \pm 0.05$ \\
\hline C. K. (2) & & & 62.6 & 23.4 & 40.5 & - & 一 & $0.04 \pm 0.01$ & $0.31 \pm 0.03$ \\
\hline M. W. (1)\| & $\mathrm{F}$ & 21 & 51.6 & 29.1 & 48.3 & 26.7 & 2.0 & $0.03 \pm 0.01$ & $0.25 \pm 0.02$ \\
\hline M. W. (2) & & & 51.3 & 24.9 & 45.2 & - & - & $0.04 \pm 0.01$ & $0.23 \pm 0.02$ \\
\hline Mean & & & & 25.3 & 41.9 & 30.1 & 2.7 & 0.04 & 0.35 \\
\hline$\pm \mathrm{SD}$ & & & & 2.6 & 4.4 & 4.0 & 1.0 & 0.02 & 0.09 \\
\hline
\end{tabular}

* Determined with ${ }^{51} \mathrm{C}$-labeled RBC's and venous hematocrit.

$\ddagger 5 \mathrm{mg} / \mathrm{kg}$ dose.

$\$$ Mean \pm SEM for at least 10 determinations.

II Intervals between paired studies were 1 month (S. B., C. K., M. W.), 2 months (G. M.), 4 months (J. L.), and 10 months (D. R.).

I Mean red blood cell life span determined from ferrokinetic studies with ${ }^{59} \mathrm{Fe} .{ }^{51} \mathrm{Cr}$ survival not done.

The values of the model parameters for each of the 19 studies were averaged to get a weighted group mean for each parameter. The weight given to the parameters for each study was based on the variances and covariances of the parameters of that study, in accordance with a maximal likelihood estimate (29). Correlation coefficients between the model parameters were also calculated.

The assumptions implicit in the mathematical techniques employed in this study have recently been reviewed (9). An explicit statement of these assumptions, and of the errors which may result from them; a more detailed derivation of the equations of the model; and a set of computer generated "normal" plasma, fecal, and urine data corresponding to the usual sampling times have been prepared as an appendix to this paper. ${ }^{2}$

${ }^{2}$ This material has been deposited as Document No. 00555 with the National Auxiliary Publications Service, c/o Information Sciences, Inc., 909 Third Ave., New York 10022. A copy may be secured by citing the document number and by remitting $\$ 3.00$ for photocopies or $\$ 1.00$ for microfiche.

\section{RESULTS}

Evaluation of methods. An essential assumption in these studies is that the radioactivity extracted from plasma into the nonpolar phase of the Weber-Schalm solvent system is an accurate reflection of the unconjugated bilirubin- ${ }^{14} \mathrm{C}$ content of the plasma sample. This requires that $(a)$ the extraction of unconjugated bilirubin into the lower layer be highly efficient and (b) conjugated bilirubin $-{ }^{14} \mathrm{C}$ and any other labeled metabolic by-products of the injected isotopic bilirubin be efficiently excluded from the lower layer. This has been confirmed by the following studies:

(a) The partition coefficient of the Weber-Schalm system for unconjugated bilirubin, determined as described above, was found to be $0.95 \pm 0.05$, indicating highly efficient extraction of unconjugated bilirubin from the plasma into the lower layer. In previously described 


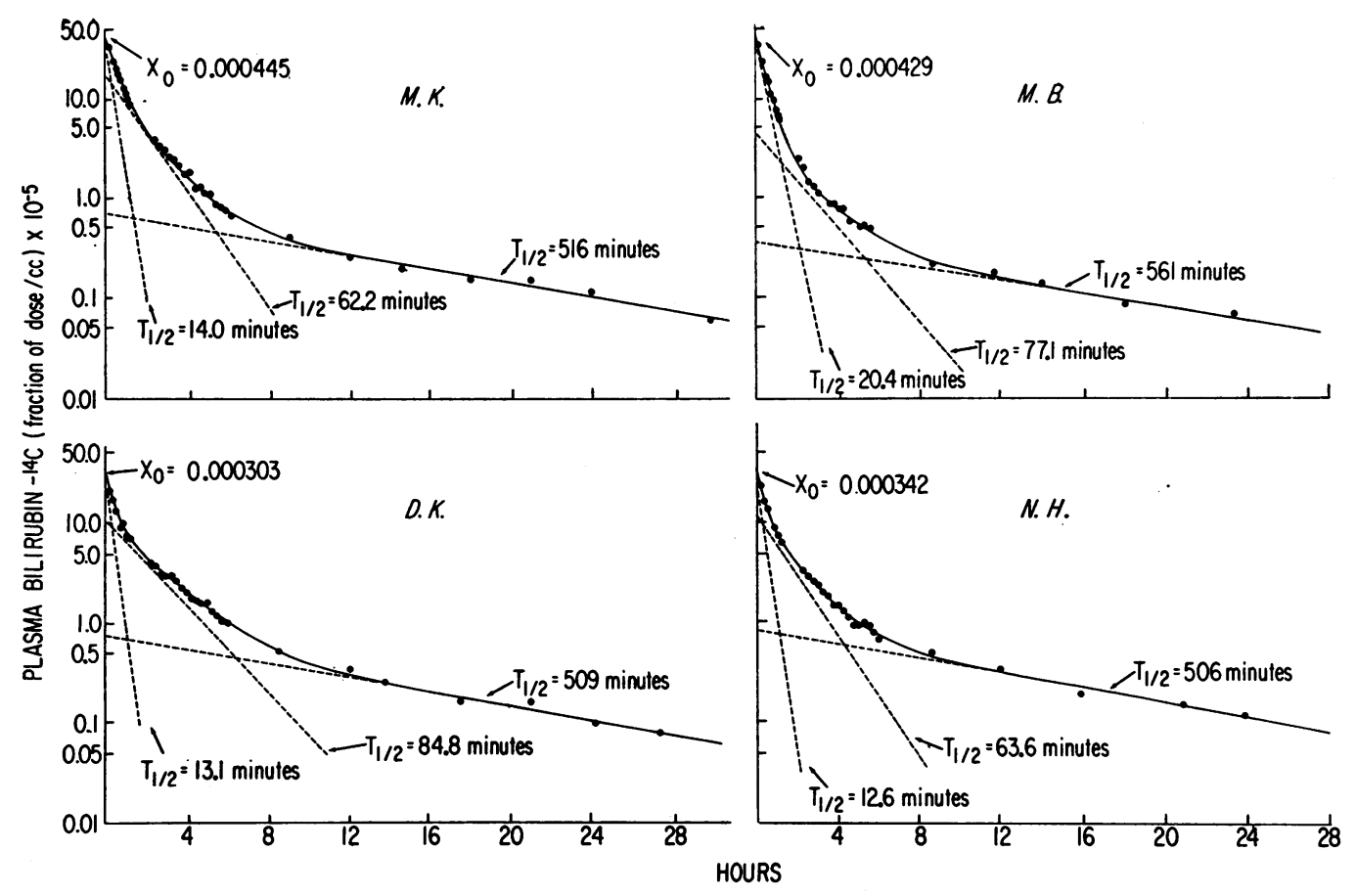

Figure 2 Bilirubin- $-{ }^{14} \mathrm{C}$ disappearance curves in four subjects. Solid curve represents the computer fit to a three exponential function. Dotted lines are the individual exponential components. $\mathrm{X}_{0}$, the value at zero time, is the reciprocal of the initial distribution volume of the injected bilirubin $-{ }^{14} \mathrm{C}$.

studies (10), when fresh rat bile containing conjugated bilirubin ${ }^{14} \mathrm{C}$ was added to plasma and the sample extracted, a minimum of $92 \%$ of the radioactivity was recovered in the polar, upper layer.

(b) In studies previously described (10), the specific activity (SA) of plasma unconjugated bilirubin $-{ }^{14} \mathrm{C}$ determined by counting and diazotization of the lower layer agreed with the specific activity obtained by recrystallization of unconjugated bilirubin from the lower layer with unlabeled carrier. The previous studies were limited to samples obtained during the first $6 \mathrm{hr}$ after injection. We crystallized unconjugated bilirubin from the lower layer of the $27 \mathrm{hr}$ sample in three studies. The ratio of SA (crystals):SA (Weber-Schalm) varied from 0.90 to 1.11 .

To obtain an independent estimate of heme turnover for comparison with the bilirubin production rate calculated from these studies, simultaneous measurements of bilirubin production and of carbon monoxide production were carried out in eight subjects (30). Carbon monoxide production was measured using a closed respiratory system similar to that described by Coburn, Blakemore, and Forster (31). Blood CO content was determined gas chromatographically on $0.1 \mathrm{ml}$ samples as previously described (32). The subjects studied included three nor- mal ones (J. L., N. H., R. G.) and five patients with unconjugated hyperbilirubinemia. Of the patients, three were hemolysing and had bilirubin production rates of 453-1650 mg/day. There was good agreement between the measurements of bilirubin production and carbon monoxide production $(r=0.96)$. When both were expressed in millimoles per day, the average ratio of carbon monoxide production: bilirubin production for the eight studies was $1.03 \pm 0.20$ (30). Although the overall agreement was good, a small physiologic discrepancy between $\mathrm{CO}$ and bilirubin production cannot be ruled out by these studies because of the relatively low precision of the $\mathrm{CO}$ method, especially in subjects with normal rates of heme turnover.

Experimental data. Preliminary laboratory data in the 13 normal subjects are summarized in Table I. Plasma bilirubin $-{ }^{14} \mathrm{C}$ disappearance curves in four typical studies are illustrated in Fig. 2. The data for each study (expressed as fraction of dose per cubic centimeter of plasma) were fitted to a three exponential function of the form $q(t)=K\left(A_{11} e^{-\alpha_{1} t}+A_{12} e^{-\alpha_{2} t}+A_{13} e^{-\alpha_{3} t}\right)$, where $A_{11}+A_{12}+A_{13}=1 . K$ is a proportionality constant equal to the reciprocal of the initial volume of distribution of the injected bilirubin. Values (mean $\pm \mathrm{SD}$ ) of $\mathrm{K}$, the in- 
TABLE II

Model-Independent Parameters Calculated from the Plasma Clearance Curve of Unconjugated Bilirubin-14C and the Plasma Concentration of Unconjugated Bilirubin

\begin{tabular}{|c|c|c|c|c|c|c|}
\hline Subject & $\mathbf{M}_{\mathbf{1}}$ & $k_{0}$ & $\mathrm{C}_{\mathrm{BR}}$ & Efficiency & BRP & RBCLS \\
\hline & $m g$ & $\min ^{-1}$ & $m l / m i n$ & $\%$ & $m g / d a y$ & days \\
\hline L. $\mathbf{H}$. & $8.5 \pm 0.6$ & $0.021 \pm 0.002$ & $61.7 \pm 6.4$ & 7.5 & $254 \pm 31$ & 127 \\
\hline D. R. (1) & $19.3 \pm 3.0$ & $0.013 \pm 0.001$ & $58.4 \pm 8.3$ & 4.6 & $366 \pm 61$ & 94 \\
\hline D. R. (2) & $20.1 \pm 2.7$ & $0.014 \pm 0.001$ & $63.0 \pm 6.4$ & 5.0 & $392 \pm 60$ & 88 \\
\hline M. B. & $6.9 \pm 0.7$ & $0.022 \pm 0.002$ & $51.2 \pm 6.9$ & 7.9 & $223 \pm 31$ & 106 \\
\hline N. H. & $12.3 \pm 2.3$ & $0.016 \pm 0.002$ & $48.1 \pm 10.0$ & 5.7 & $291 \pm 68$ & 111 \\
\hline R. G. & $15.2 \pm 1.0$ & $0.012 \pm 0.001$ & $39.7 \pm 2.5$ & 4.3 & $273 \pm 22$ & 116 \\
\hline D. $\mathrm{K}$. & $14.8 \pm 2.8$ & $0.014 \pm 0.002$ & $46.5 \pm 8.6$ & 5.0 & $301 \pm 69$ & 95 \\
\hline J. L. (1) & $19.7 \pm 1.5$ & $0.012 \pm 0.001$ & $49.4 \pm 3.5$ & 4.3 & $341 \pm 31$ & 117 \\
\hline J. L. (2) & $23.9 \pm 2.6$ & $0.009 \pm 0.001$ & $39.7 \pm 5.2$ & 3.2 & $308 \pm 45$ & 108 \\
\hline G. M. (1) & $13.0 \pm 1.9$ & $0.014 \pm 0.001$ & $34.7 \pm 5.3$ & 5.0 & $256 \pm 44$ & 103 \\
\hline G. M. (2) & $15.6 \pm 2.7$ & $0.012 \pm 0.002$ & $40.6 \pm 7.2$ & 4.3 & $273 \pm 59$ & 111 \\
\hline M. K. & $7.5 \pm 1.4$ & $0.018 \pm 0.002$ & $39.2 \pm 7.2$ & 6.4 & $194 \pm 44$ & 84 \\
\hline L. B. & $10.9 \pm 1.9$ & $0.011 \pm 0.002$ & $26.0 \pm 4.1$ & 3.9 & $166 \pm 30$ & 107 \\
\hline S. B. (1) & $13.2 \pm 1.7$ & $0.013 \pm 0.001$ & $31.9 \pm 4.7$ & 4.6 & $237 \pm 40$ & 88 \\
\hline S. B. (2) & $15.7 \pm 2.7$ & $0.011 \pm 0.001$ & $43.7 \pm 7.9$ & 3.9 & $248 \pm 49$ & 87 \\
\hline C. K. (1) & $10.2 \pm 1.9$ & $0.018 \pm 0.002$ & $54.3 \pm 8.5$ & 6.4 & $263 \pm 54$ & 86 \\
\hline C. K. (2) & $10.6 \pm 1.8$ & $0.016 \pm 0.003$ & $55.0 \pm 12.1$ & 5.7 & $246 \pm 58$ & 84 \\
\hline M. W. (1) & $6.5 \pm 0.9$ & $0.022 \pm 0.003$ & $56.7 \pm 11.1$ & 7.9 & $208 \pm 43$ & 102 \\
\hline M. W. (2) & $5.7 \pm 0.7$ & $0.020 \pm 0.001$ & $49.5 \pm 4.4$ & 7.1 & $162 \pm 23$ & 111 \\
\hline Mean \pm SD & $13.2 \pm 5.0$ & $0.015 \pm 0.004$ & $47 \pm 10$ & $5.4 \pm 1.4$ & $263 \pm 60$ & $101 \pm 13$ \\
\hline
\end{tabular}

For definition of symbols, see text section on Data Analysis.

tercepts, and rate constants for the 19 studies are as follows:

$$
\begin{aligned}
\mathrm{A}_{11} & =0.66 \pm 0.17 & & \alpha_{1}=0.044 \pm 0.013 \mathrm{~min}^{-1} \\
\mathrm{~A}_{12} & =0.31 \pm 0.16 & & \alpha_{2}=0.010 \pm 0.003 \mathrm{~min}^{-1} \\
\mathrm{~A}_{13} & =0.03 \pm 0.02 & & \alpha_{3}=0.0012 \pm 0.0002 \mathrm{~min}^{-1} \\
\mathrm{~K} & =0.00033 \pm 0.00007 & &
\end{aligned}
$$

The average half-times for the three exponential components were 18, 81 , and $578 \mathrm{~min}$. Values for each of the individual studies are available on request.

The model-independent parameters derived from these data and from the mean concentration of plasma unconjugated bilirubin are presented in Table II. The initial distribution volume of the injected albumin-bound bilirubin $-{ }^{14} \mathrm{C}$ was $46 \pm 10 \mathrm{cc} / \mathrm{kg}$, similar to the "estimated albumin distribution volume" of $45.6 \pm 5.6 \mathrm{cc} / \mathrm{kg}$. Since plasma bilirubin is entirely albumin-bound under normal conditions (33), these data suggest that the injected bilirubin ${ }^{24} \mathrm{C}$ behaved physiologically in this regard.

The plasma unconjugated bilirubin pool averaged 13 $\pm 5 \mathrm{mg}$ in the 19 normal studies. The rate constant k. (the amount of bilirubin irreversibly lost from the system per minute, expressed as a fraction of the plasma pool) equaled $0.015 \pm 0.004$. This corresponds to an extrartion efficiency of $5.4 \pm 1.4 \%$, and a bilirubin clearance of $47 \pm 10 \mathrm{cc} / \mathrm{min}$. The extraction of bilirubin is thus appreciably less than that of sulfobromophthalein (34) or indocyanine green (35). The per cent of injected bilirubin- ${ }^{1 \mathrm{C}} \mathrm{C}$ retained in plasma at $4 \mathrm{hr}$ was 5.0 $\pm 1.9 \%$.
(3)

(I)
(2)

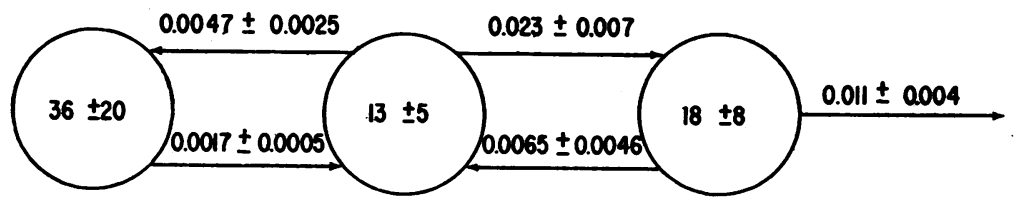

FIGURE 3 Weighted mean values for the parameters of the model. Compartments and pathways correspond to Fig. 1. Values within the circles are pool sizes (mean $\mathbf{I S D}_{\mathrm{S}}$ ) in milligrams. Values above each arrow represent fractional transfer rates per minte in the direction of the arrow. 
TABLE 111

Model-Dependent Parameters

\begin{tabular}{|c|c|c|c|c|c|c|c|c|c|}
\hline Subject & $\lambda_{21}$ & $\lambda_{12}$ & $\lambda_{02}$ & $\lambda_{31}$ & $\lambda_{13}$ & $\mathrm{M}_{2}$ & $\mathrm{M}_{3}$ & MCR & $\begin{array}{l}\text { Hepatic } \\
\text { uptake }\end{array}$ \\
\hline & $\min ^{-1}$ & $\min ^{-1}$ & $\min ^{-1}$ & $\min ^{-1}$ & $\min ^{-1}$ & $m g$ & $m g$ & & $\mu \mathrm{g} / \min$ \\
\hline L. H. & 0.034 & 0.0072 & 0.012 & 0.0097 & 0.0010 & 15.2 & 80.1 & 3.3 & 286 \\
\hline D. R. (1) & 0.022 & 0.0094 & 0.014 & 0.0049 & 0.0020 & 18.7 & 46.7 & 2.6 & 430 \\
\hline D. R. (2) & 0.023 & 0.0030 & 0.0044 & 0.0018 & 0.00068 & 61.9 & 51.7 & 8.5 & 458 \\
\hline M. B. & 0.028 & 0.0022 & 0.0094 & 0.0034 & 0.0014 & 16.5 & 16.6 & 4.0 & 191 \\
\hline N. H. & 0.034 & 0.014 & 0.013 & 0.0051 & 0.0019 & 15.4 & 33.7 & 2.4 & 414 \\
\hline R. G. & 0.015 & 0.0011 & 0.0057 & 0.0022 & 0.0018 & 33.1 & 18.6 & 5.8 & 226 \\
\hline D. K. & 0.033 & 0.014 & 0.010 & 0.0033 & 0.0017 & 20.8 & 27.7 & 3.2 & 496 \\
\hline J. L. (1) & 0.016 & 0.0019 & 0.0052 & 0.0034 & 0.0014 & 45.3 & 49.2 & 4.2 & 322 \\
\hline J. L. (2) & 0.016 & 0.0082 & 0.011 & 0.0070 & 0.0028 & 20.1 & 49.1 & 2.1 & 379 \\
\hline G. M. (1) & 0.024 & 0.014 & 0.019 & 0.0050 & 0.0020 & 9.3 & 32.3 & 1.3 & 311 \\
\hline G. M. (2) & 0.022 & 0.014 & 0.018 & 0.0049 & 0.0020 & 10.6 & 38.7 & 1.6 & 342 \\
\hline M. K. & 0.032 & 0.011 & 0.014 & 0.0036 & 0.0017 & 9.5 & 16.6 & 3.3 & 241 \\
\hline L. B. & 0.018 & 0.013 & 0.018 & 0.0022 & 0.0011 & 6.3 & 22.6 & 1.1 & 199 \\
\hline S. B. (1) & 0.022 & 0.0050 & 0.0063 & 0.0021 & 0.0011 & 26.3 & 25.3 & 4.3 & 295 \\
\hline S. B. (2) & 0.022 & 0.013 & 0.014 & 0.0061 & 0.0024 & 12.6 & 39.8 & 2.8 & 341 \\
\hline C. K. (1) & 0.033 & 0.010 & 0.012 & 0.0052 & 0.0018 & 15.0 & 29.9 & 3.6 & 333 \\
\hline C. K. (2) & 0.033 & 0.014 & 0.014 & 0.0078 & 0.0022 & 12.3 & 37.3 & 3.2 & 349 \\
\hline M. W. (1) & 0.032 & 0.0072 & 0.016 & 0.0100 & 0.0019 & 9.1 & 33.4 & 3.5 & 300 \\
\hline M. W. (2) & 0.031 & 0.0054 & 0.0096 & 0.0062 & 0.0015 & 11.6 & 23.3 & 5.0 & 175 \\
\hline
\end{tabular}

For definition of symbols, see Fig. 1 and text section on Data Analysis.

The average BRP for the 19 studies was $263 \pm 60$ $\mathrm{mg} /$ day. This corresponded to a mean red blood cell life span of $101 \pm 13$ days. When calculated in terms of body weight, $\mathrm{BRP}$ in males $(3.8 \pm 0.5 \mathrm{mg} / \mathrm{kg}$ per day) was not significantly different than that for females (3.9 \pm $0.6 \mathrm{mg} / \mathrm{kg}$ per day). Because the total red cell volume in females $(25.3 \pm 2.6 \mathrm{cc} / \mathrm{kg})$ is smaller than in males $(28.7 \pm 3.8 \mathrm{cc} / \mathrm{kg})$, the calculated mean red blood cell life span was shorter in the women volunteers $(94 \pm 11$ days vs. $107 \pm 11$ days for men). This difference is significant (Student's $t$ test, $P<0.05$ ). RBCLS is the only parameter for which a significant sex difference was observed.

Results of multicompartmental analysis are presented in Table III and Fig. 3. The intercompartmental rate constants ( $\lambda$ 's) were determined by the data with an average precision of $\pm 15 \%$.

The results indicate that the initial uptake of unconjugated bilirubin into compartment 2 (the liver) averaged $2.3 \pm 0.7 \%$ of the plasma $\mathrm{pool} / \mathrm{min}$ (Fig. 3 ). This corresponds to a flux of $320 \pm 88 \mu \mathrm{g} / \mathrm{min}$, and represents approximately $8 \%$ of the presented load. Net extraction $\left(k_{e}\right)$ is appreciably less than initial uptake $\left(\lambda_{21}\right)$ due to a reflux of unconjugated bilirubin from liver to plasma. The fraction $\lambda_{02} / \lambda_{22}$ averaged 0.63 , indicating that only $63 \%$ of the bilirubin entering the hepatic pool is conjugated. The remaining $37 \%$ is accounted for by bilirubin which returns to plasma unaltered.

Solution of the steady-state equations of the model indicated that the hepatic pool of unconjugated bilirubin averaged 1.5 times the plasma pool. Since the total hepatic volume (estimated as equal to $2 \%$ of body weight) is less than the plasma volume, this implies the existence of a concentration gradient between liver and plasma. The average value of MCR was 3.5:1 (range 1.1-8.5). Since the bile bilirubin concentration is more than 30 $\mathrm{mg} / 100 \mathrm{ml}$, representing a 50 - to 100 -fold concentration with respect to plasma, it is clear that the bulk of this gradient is achieved by processes not accounted for in the current model, such as the active transport of conjugated bilirubin into the bile canaliculus (36) and the absorption of water in the gall bladder (37).

Of the total flux out of the plasma, the fraction $\lambda_{31} / \lambda_{11}$ goes to the extravascular pool. This fraction equaled $16 \pm 6 \%$ in these studies. The mean sojourn $(\bar{t})$ of a bilirubin molecule in the extravascular pool (calculated as $1 \div \lambda_{13}$ ) was $9.8 \mathrm{hr}$. This corresponds closely to the value $\bar{t}=9.6 \mathrm{hr}$ for albumin in the rapidly exchanging extravascular albumin pool, as defined with ${ }^{18}$ I-labeled albumin (38). On the other hand, for 18 of the studies (excluding L. H.) ${ }^{3}$ the extrahepatic, extravascular bili-

\footnotetext{
${ }^{3}$ In subject L. H., who was the first case in whom a 3rd exponential was sought, inopportune choice of sampling times led to an uncertainty of $\pm 40 \%$ in the calculated size of the extravascular pool, although the area under the curve and the model-independent parameters were well determined. The average uncertainty in the size of the extravascular pool was $10.7 \pm 4.4 \%$ (range $4.4-22.8$ ) in the remaining 18 studies.
} 
rubin pool averaged $2.6 \pm 0.8$ times the plasma pool. This is greater than the ratio of $1.5: 1$, usually reported for albumin.

Average recovery of injected isotope in the stool was $89.7 \%$ by day 4 and $92.5 \%$ by day 7 (Fig. 4 ). $48 \%$ of injected isotope appeared during the second day. Because the data are insufficient to resolve the large number of distinct processes presumably occurring between conjugation and the appearance of the labeled bilirubin in the feces, no attempt was made to incorporate these data into the model. However, our previously reported estimate of $95 \%$ of injected isotope recovered in $24 \mathrm{hr}$ in a patient with an external biliary fistula (10), and the average gastrointestinal transit time of $24 \mathrm{hr}$ in the subjects presented here, as determined with blue stool markers (39), indicates a delay in the biliary passages and gastrointestinal tract of up to 2 days for approximately $40 \%$ of the excreted isotope. This presumably results in part from temporary storage in the gall bladder. Average recovery of isotope in the urine, $3.1 \%$ in 7 days, was not significantly different from that observed in the Crigler-Najjar syndrome $(2,4)$. Although the chemical form of this isotope was not determined, it is unlikely to be unconjugated bilirubin, and therefore, no $\lambda$ for urinary excretion was included in the model. Small amounts of urobilinogen, conjugated bilirubin, and trace impurities in the injected material (particularly during the first 24 $\mathrm{hr}$ ) are presumed to account for most of the urinary isotope. These results are in sharp contrast to the studies in children with biliary atresia (5), in whom $0-5 \%$ of

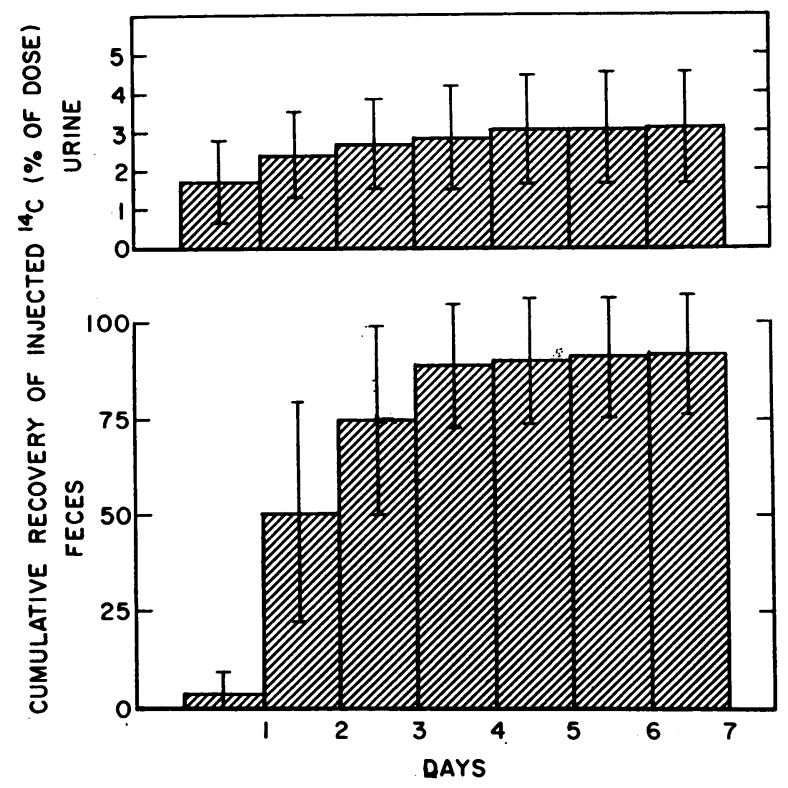

FIGURe 4 Cumulative recovery of injected ${ }^{10} \mathrm{C}$ in urine and feces. Values plotted are means \pm 2 sd. isotope was recoverable in the feces, and $44-77 \%$ in the urine. In these children $60 \%$ of the urinary isotope could be recovered as crystallizable bilirubin.

The findings in the six individuals studied twice require separate comment. As illustrated in Fig. 5, the curves obtained for each pair of studies were similar, but not superimposable. When differences existed, they were most marked in the later portions of the curves. Although the shape of the curve varied somewhat, the area under the curve was highly reproducible for each individual. The values of the model-independent parameters, which depend largely on the area under the curve, were therefore also reproducible within the limits of experimental error in each of the six subjects (Table II). On the other hand, values for some of the intercompartmental rate constants varied from study to study in five of these six individuals (Table III). The value for $\lambda_{21}$ (hepatic uptake) was highly reproducible in all cases. Differences, when they occurred, were restricted to the other four intercompartmental rate constants. For each of the paired studies, a single ratio $\mathrm{R}$ could be found so that the value $\left(\left[\lambda_{11}\right]_{\text {study } 1} \div\left[\lambda_{11}\right]_{\text {study } 2}\right)=R$, for $\lambda_{11}=\lambda_{02}, \lambda_{12}, \lambda_{31}$, and $\lambda_{13}$. This pattern has definite physiological implications. Since $k_{e}=\lambda_{21} \cdot \lambda_{02} /\left(\lambda_{12}+\lambda_{02}\right)$ and $\mathrm{M}_{3} / \mathrm{M}_{1}=\lambda_{31} / \lambda_{13}$, it is clear that this pattern is one which tends to maintain a constant value for $k_{e}$ and for the size of the extravascular pool relative to plasma. At the same time, significant changes occurred in the hepatic pool size and the liver:plasma concentration gradient. We have no explanation for this finding. The values of $R$ ranged from $0.34 \pm 0.02$ (D. R.) to $2.52 \pm$ 0.35 (S. B.). In G. M., $R$ was $0.98 \pm 0.04$. The greatest changes occurred in D. R., whose studies were 10 months apart; J. L., who lost 54 pounds betwen studies; and S. B. who was studied in opposite phases of the menstrual cycle.

The observed range of plasma unconjugated bilirubin${ }^{14} \mathrm{C}$ disappearance curves in the 19 studies is shown in Fig. 6. Computer-calculated values for the isotope content of the hepatic and extravascular pools and the cumulative fraction of bilirubin $-{ }^{14} \mathrm{C}$ conjugated at various times after injection are presented in Fig. 7.

\section{DISCUSSION}

In the initial report describing the techniques employed in the current study we indicated that, over an experimental period of $4-8 \mathrm{hr}$, the plasma clearance curve of labeled unconjugated bilirubin could be resolved into two decreasing exponential functions (10). The data were therefore analyzed according to a two-pool model previously postulated by Billing, Williams, and Richards on the basis of bilirubin loading tests (40). Although there were characteristic differences in the curves and model parameters between normals and a number of 


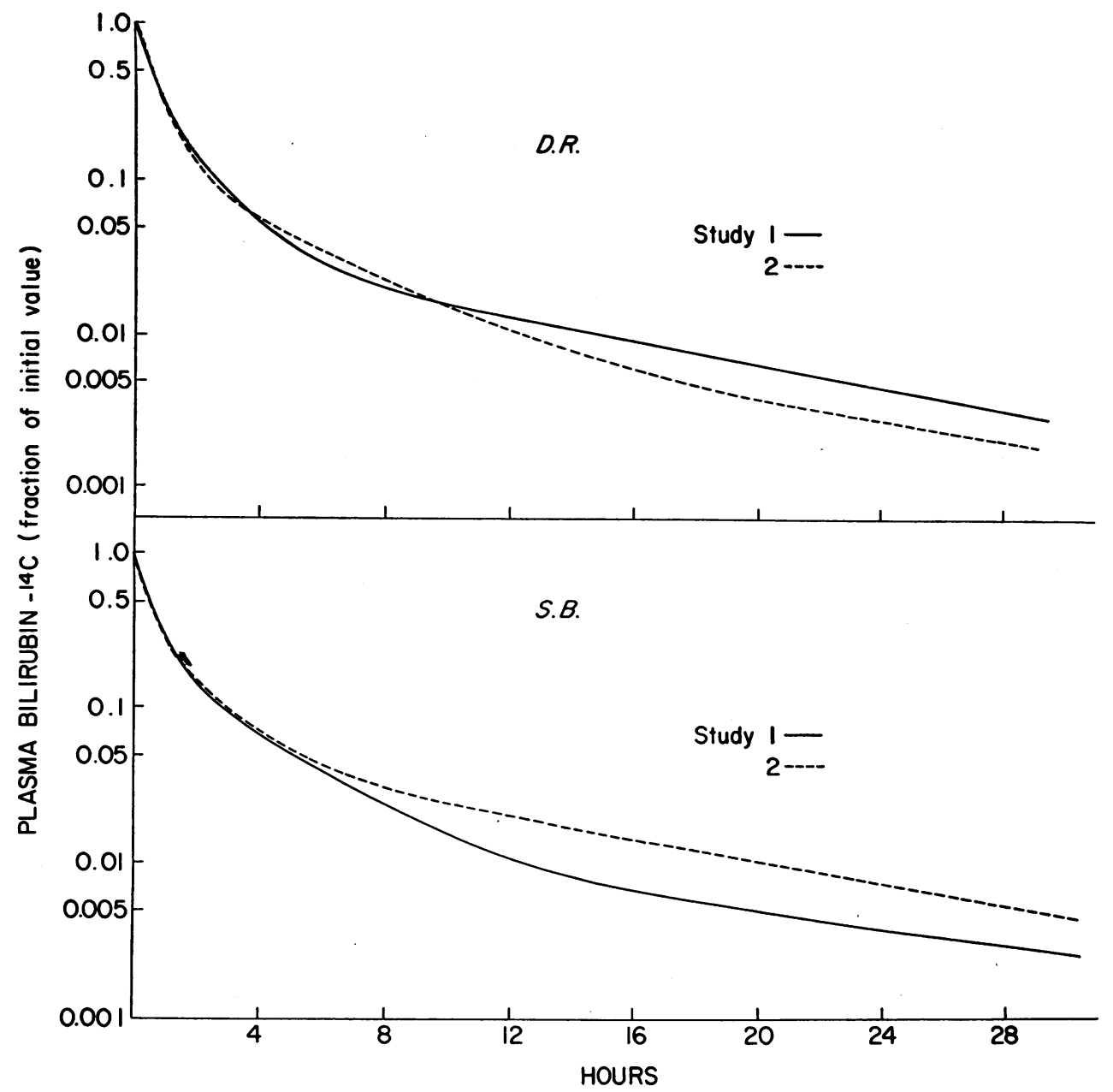

FIGURE 5 Paired bilirubin- ${ }^{14} \mathrm{C}$ clearance studies in two subjects. Lines represent computer fits to the data. Individual data points are not presented, but scatter in these studies was similar to that in Fig. 2. To facilitate comparison between studies, curves have been normalized to an initial value of unity.

disease entities, similar to those observed by Billing et al. (40), the model was inadequate for two reasons. First, it failed to provide for an extravascular bilirubin pool. In addition, although bilirubin turnover rates calculated from these studies were clearly higher in patients with hemolysis or increased ineffective erythropoiesis than in normals, the values in normal subjects corresponded to mean red blood cell life spans of 70-90 days. Since the calculated bilirubin production is inversely proportional to the area under the bilirubin ${ }^{14} \mathrm{C}$ clearance curve (23), overestimation of bilirubin production suggested underestimation of the area under the curve and led us to extend our sampling time in search of a third, slower exponential clearance component. The demonstrated existence of this component requires the addition of a third exchanging pool to the bilirubin model, and leads to calculations of red cell life span in normals more consistent with results obtained from standard methods. The independent observation by Araki and Kashima, in Japan, of a three exponential plasma clearance curve for unconjugated bilirubin- ${ }^{8} \mathrm{H}$, and postulation of an identical three compartment model, has recently come to our attention $(41,42)$.

The most general three compartment model consistent with our data has three exchanging bilirubin pools with nine rate constants ( $\lambda$ 's) including three modes of exit. Accurate determination of all of these parameters is beyond the resolution of our data, which can account for up to five rate constants (26). The selection of a model providing for only a single mode of exit is consistent with the current understanding of bilirubin metabolism. Only in the Crigler-Najjar syndrome and the Gunn rat is a measurable fraction of unconjugated bilirubin eliminated from sites other than the liver, 


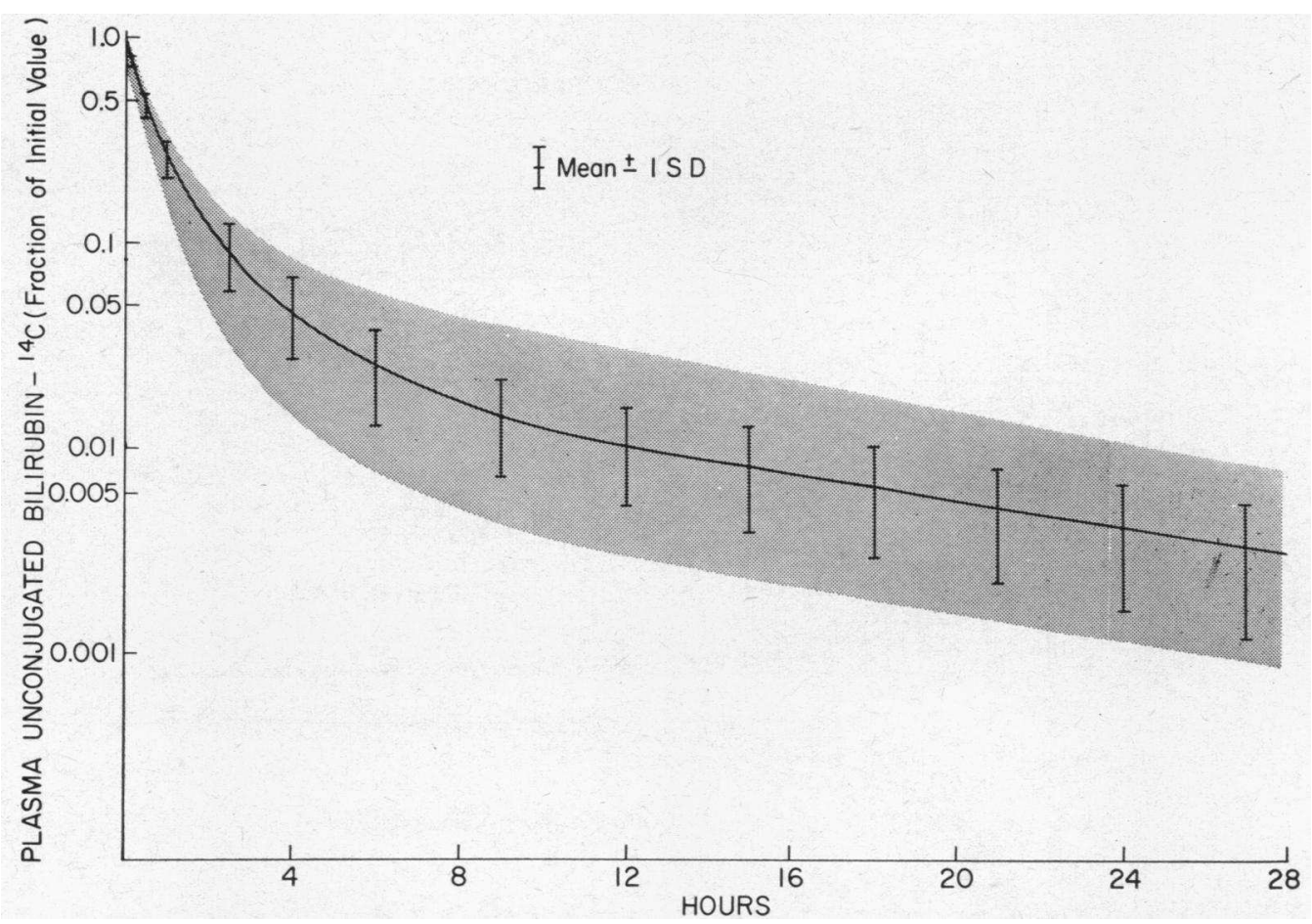

FIGURE 6 Composite of 19 plasma bilirubin- ${ }^{14} \mathrm{C}$ clearance studies in 13 normal subjects. Stippled area is the observed range. Solid line is the "average" curve corresponding to the mean values for the lambdas.

or by pathways other than conjugation (2). Selection of a model in which exchange between the liver and plasma is bidirectional was based on studies in which ALA-4- ${ }^{14} \mathrm{C}$ was administered intravenously to four subjects. Using the method of Weber and Schalm (8), we were able to demonstrate that virtually all of the labeled bilirubin subsequently appearing in the plasma was unconjugated." Since several investigators have indicated that the liver is the principle source of the labeled plasma bilirubin appearing under these conditions $(43,44)$, our results indicate the existence of a pathway by which unconjugated bilirubin in the liver cell may reflux to plasma. A similar conclusion is suggested by the studies of Robinson, Owen, Flock, and Schmid (45), who found bilirubin- ${ }^{3} \mathrm{H}$ in plasma following ALA- ${ }^{3} \mathrm{H}$ administration to a child with Crigler-Najjar syndrome, in whom all plasma bilirubin is unconjugated. The presence of a bidirectional exchange of bilirubin between plasma and liver is also consistent with the general pattern of hepatic uptake of other organic anions such as BSP (46).

Although our studies indicate the existence of two extravascular bilirubin pools, one of which exchanges

\footnotetext{
' Howe, R. B., P. D. Berk, J. R. Bloomer, and N. I. Berlin. Linear systems analysis applied to the labeling of plasma bilirubin after administration of isotopic glycine and $\delta$-aminolevulinic acid. In preparation.
}

with plasma rapidly, and the other relatively slowly, identification of these compartments as hepatic and extrahepatic extravascular is an assumption which requires independent verification. This assumption is supported by several lines of evidence. The similarity between the turnover time of compartment 3 and the known kinetics of extravascular albumin has already been mentioned. In Fig. 8 we have compared the cumulative recovery of bilirubin ${ }^{14} \mathrm{C}$ from the bile of a patient with an external biliary fistula with the curve of cumulative conjugation calculated by computer from the plasma bilirubin- ${ }^{14} \mathrm{C}$ clearance data in the same patient. Since the rate of bilirubin excretion in the bile must reflect in part the rate at which bilirubin enters the liver and is conjugated, the similarity of the experimental and computer-generated curves (allowing a delay for passage through the biliary tree) strongly supports the concept that compartment 2 is within the liver. This concept is also supported by a considerable body of data in the rat. Although the mechanisms involved are presumed to be similar in the two species, hepatic uptake and biliary excretion of bilirubin are known to be much more rapid in the rat than in man. This can be inferred from the fact that bilirubin is virtually undetectable in normal rat plasma (47), even though the bilirubin production rate $(\mathrm{mg} / \mathrm{kg}$ per day), estimated from the total 


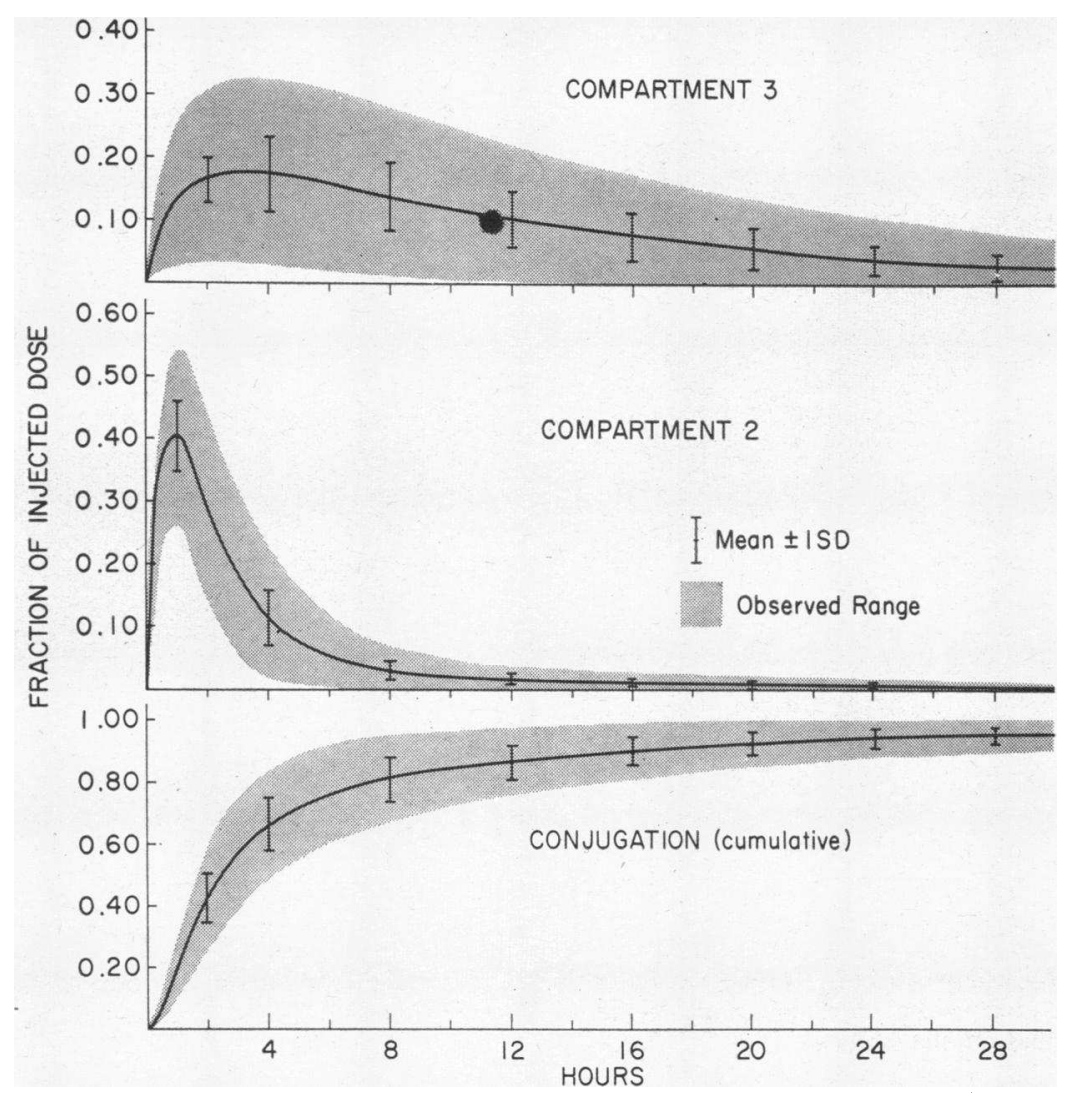

FIGURE 7 Isotope content of the extrahepatic extravascular (upper panel) and hepatic (middle panel) unconjugated bilirubin pools; and cumulative fraction of bilirubin ${ }^{14} \mathrm{C}$ conjugated (lower panel) at various times after injection. This information is calculated by computer from the experimental bilirubin- ${ }^{14} \mathrm{C}$ plasma clearance data and the equations of the model.

red cell volume (48) and life span (49), is approximately the same as in man. Furthermore, intravenously injected unconjugated radiobilirubin is cleared from the plasma of the rat with an initial $\mathrm{T}_{\mathrm{i}}$ of only 1-2 min $(50,51)$, and $80-95 \%$ of the injected dose is recoverable in the bile at the end of $1 \mathrm{hr}(50,52)$. In man, the initial plasma $T$ for intravenously injected bilirubin- ${ }^{14} \mathrm{C}$ averaged $18 \mathrm{~min}$ in the current studies, and recovery of isotopic bilirubin in the bile was correspondingly slow (Fig. 8). Differences between man and rat may reflect the relatively greater size of the rat liver, a more rapid metabolic rate, differences in hepatic blood flow, or other unknown factors. Allowing for the greater over-all velocity of bilirubin clearance and excretion in the rat, the shape of the experimentally determined curve of intrahepatic radioactivity after intravenous administration of unconjugated radiobilirubin in the rat $(52,53)$ is strikingly similar to that calculated for compartment 2 in the current studies, and quite different from that observed for compartment 3 (Fig. 7). Furthermore, a bilirubin concentration gradient of 2 - to 3 -fold between liver and plasma, similar to that observed in the current studies, has also been observed in normal rats (50), although jaundiced Gunn rats, in whom the plasma bilirubin concentration may be increased more than 50 times above the normal level, apparently can not concentrate bilirubin in the course of hepatic uptake and storage (54). This may reflect saturation of intracellular bilirubin-binding proteins (55) at high plasma bilirubin concentrations.

The proposed compartmental model is a conceptualization of the exchanging bilirubin system as seen by a single technique, that of isotope tracer kinetics. The rate constants $\left(\lambda^{\prime} s\right)$ are an accurate representation of the over-all rates of transfer between compartments but are not necessarily representative of a single physiologic process. They may equally well represent the composite of a number of sequential processes which cannot be resolved by the data. Thus, the current studies are equally compatible with the active transport of bilirubin into the liver cell with back-diffusion to plasma, the so-called "pump and leak" system, or with passive diffusion un- 


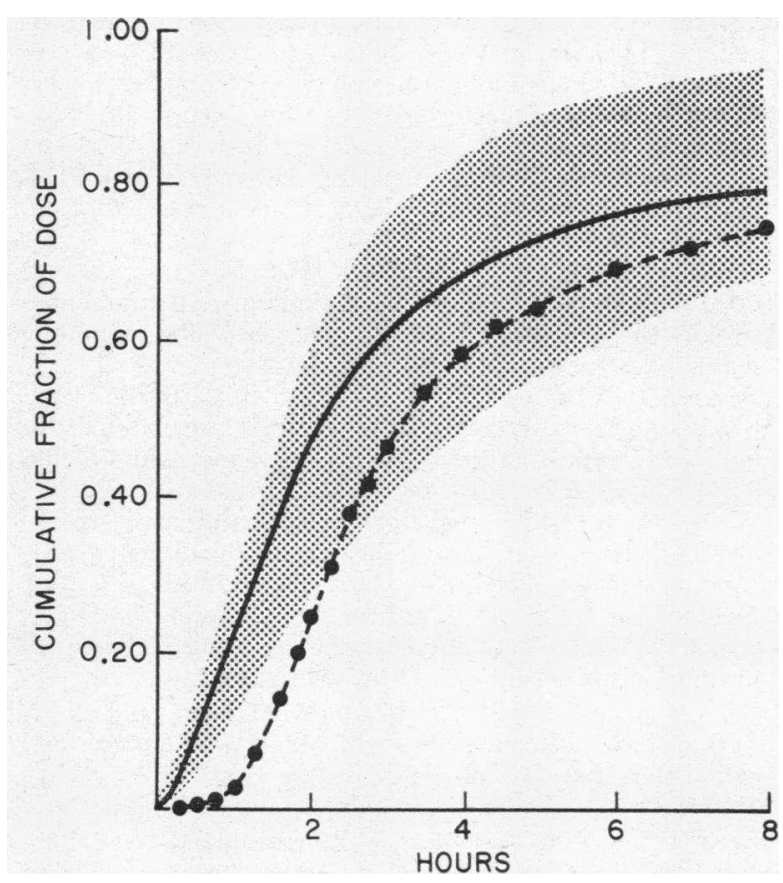

FIgURE 8 Cumulative recovery in the bile of intravenously injected bilirubin $-{ }^{14} \mathrm{C}$ in a patient with an external biliary fistula but with normal liver function (--- $-\bullet)$. This data parallels the computer-calculated curve of cumulative bilirubin $-{ }^{14} \mathrm{C}$ conjugation in the same patient (solid line), with a time lag of approximately $1 \mathrm{hr}$. Volume of the biliary tree, calculated from this time lag and the average bile flow of $0.3 \mathrm{ml} / \mathrm{min}$ agrees closely with the value of $20 \mathrm{ml}$ determined at operation by the injection of radiographic contrast media. Stippled area corresponds to the normal range for conjugation shown in Fig. 7.

der the influence of intra- and extrahepatic bilirubinbinding proteins with different association constants. A pair of such intrahepatic binding proteins has recently been described (55). Studies employing various perturbations, such as the combination of tracer studies with bilirubin loading tests or the use of hormones or drugs, may make it possible to further resolve the $\lambda$ 's into component processes $(24,56)$.

The values for VDBR in the current study, as well as our initial report (10), are slightly, although not significantly, larger than values for the plasma volume determined with albumin $-{ }^{131} \mathrm{I}(57,58)$, and the ratio of VDBR: "estimated albumin distribution volume" = $1.04 \pm 0.10$. Therefore, the possible existence of an additional small pool, equivalent to about $5 \%$ of the plasma volume, which equilibrates very rapidly with plasma, cannot be excluded. Attempts to distinguish such a compartment from plasma in several patients by means of frequent sampling in the first $5 \mathrm{~min}$ have not produced consistent data, presumably due to incomplete mixing of injected isotope within the vascular compartment during this time. The failure to resolve a small and rapidly equilibrating compartment from "plasma" would not significantly alter the essential conclusions of the current study.

The possible role of bilirubin- $-{ }^{14} \mathrm{C}$ clearance studies in the evaluation of clinical liver disease is apparent. Such studies are particularly useful in the differential diagnosis of unconjugated hyperbilirubinemia. In such conditions, knowledge of both the bilirubin production rate and the hepatic bilirubin clearance makes possible a clear distinction between cases resulting from bilirubin overproduction and those due to defective hepatic function. Where both mechanisms are operative, the relative contribution of each to the hyperbilirubinemia can be accurately assessed (11).

The use of this technique for the rapid determination of red cell life span should also be emphasized. Blood sampling for this determination is complete within $48 \mathrm{hr}$. Although prolonged counting times are currently required, alternate methods for the production of labeled bilirubin of greater specific activity may make it possible to reduce counting time 10 -fold. ${ }^{5}$

The average value for mean red blood cell survival determined from bilirubin- ${ }^{14} \mathrm{C}$ clearance was 101 days, with a range of 84-127 days. The usually quoted figure for normal red blood cell life span is 120 days, and the bilirubin clearance study would thus, superficially, appear to provide a result which is too short. In fact, the two values are not inconsistent. The value of 120 days, obtained from the analysis of red blood cell and fecal urobilin specific activity curves after administration of labeled glycine, represents a mode for the labeled cohort, and does not take into account the random destruction of some cells which occurs even in normal individuals $(59,60)$.

It is of some interest that the mean red cell life span in the female volunteers was 94 days compared with 107 days in the males. The difference is statistically significant. A review of the extensive literature on red blood cell survival revealed that very few isotopic studies of red cell life span have been done in normal females. Using the Ashby technique, several investigators suggested an increased rate of red cell destruction in normal females, in excess of what could be attributed merely to menstrual loss (61-63).

Calculation of the mean red cell life span from the measured bilirubin production rate involves a correction for the contribution of the "early labeled peak." This has been shown to represent $10-20 \%$ of the bile pigment production in normal man $(64,65)$, and we have therefore empirically used an average value of

\footnotetext{
${ }^{5}$ Howe, R. B., P. D. Berk, J. R. Bloomer, and N. I. Berlin. Biosynthesis of a stable bilirubin- ${ }^{3} \mathrm{H}$ with all tritium atoms on the side chains. In preparation.
} 
$15 \%$ in the current studies. Using this same correction, we have found a good correlation $(r=0.86)$ between the red blood cell ${ }^{51} \mathrm{Cr}-\mathrm{T}_{3}$ and the mean red cell life span calculated from bilirubin clearance in more than 40 studies, including patients with mean red cell life spans as short at 8 days (11). On the other hand, such a correction would not be applicable in cases of erythropoietic porphyria, pernicious anemia, thalassemia, the refractory normoblastic anemias, "shunt hyperbilirubinemia," and lead poisoning $(66,67)$. All of these conditions have been shown to be associated with a significantly increased early labeled peak, possibly due to defects in the hemoglobin biosynthetic pathway.

The proposed model of unconjugated bilirubin metabolism is a simple and useful model compatible with our current data and with current concepts of hepatic physiology. It is unlikely to be the final one. As more disease states are examined, some data may be found to be incompatible with the current formulations. This will require alterations in the structure of the model so that it remains compatible with all of the available data. Finally, the development of methods for the counting of samples containing conjugated bilirubin will ultimately make it possible to add an entirely new dimension to the current model.

Values for the model-independent parameters described in the present study will not be significantly altered by these changes. Measurement of the hepatic bilirubin clearance, for example, is a useful tool in the clinical evaluation of liver disease and is independent of the structure of a particular compartmental model. Modifications in the model, resulting from refinements in methodology and wider experience, can be expected to produce increasingly more detailed insights into the hepatic handling of bilirubin in man.

\section{ACKNOWLEDGMENTS}

We are indebted to Doctors Robert Johnson and William Hammond for the preparation of bile fistula dogs used in the biosynthesis of bilirubin $-{ }^{14} \mathrm{C}$. The advice of Dr. Mones Berman regarding the mathematical aspects of the work, and of Mrs. Marjory F. Weiss (who could speak to SAAM in his own language) with the computational problems is gratefully acknowledged. The work could not have been done without the valuable technical assistance of Miss Lona A. Shepley and Mrs. Jeanne G. Waggoner.

\section{REFERENCES}

1. Ostrow, J. D., L. Hammaker, and R. Schmid. 1961. The preparation of crystalline bilirubin- $\mathrm{C}^{14}$. J. Clin. Invest. 40: 1442.

2. Schmid, R., and L. Hammaker. 1963. Metabolism and disposition of $\mathrm{C}^{\mathbf{1 4}}$-bilirubin in congenital non-hemolytic jaundice. J. Clin. Invest. 42: 1720.

3. Billing, B. H., C. H. Gray, A. Kulczycka, P. Manfield, and T. C. Nicholson. 1964. The metabolism of $\left({ }^{14} \mathrm{C}\right)-$ bilirubin in congenital non-hemolytic hyperbilirubinemia. Clin. Sci. (London). 27: 163.
4. Crigler, J. F., Jr., and N. I. Gold. 1969. Effect of sodium phenobarbital on bilirubin metabolism in an infant with congenital, nonhemolytic unconjugated hyperbilirubinemia, and kernicterus. J. Clin. Invest. 48: 42.

5. Cameron, J. L., R. M. Filler, R. L. Iber, T. Abei, and J. G. Randolph. 1966. Metabolism and excretion of $\mathrm{C}^{14}$ labeled bilirubin in children with biliary atresia $N$. Engl. J. Med. 274: 231.

6. Ibrahim, G., and C. J. Watson. 1964. Early appearance of a bile bilirubin of high specific activity after administration of $C^{14}-\delta$-aminolevulinic acid to a dog with bile fistula. Gastroenterology. 46: 299. (Abstr.)

7. Barrett, P. V. D., F. X. Mullins, and N. I. Berlin. 1966. Studies on the biosynthetic production of bilirubin- $\mathrm{C}^{14}$. An improved method utilizing $\delta$-aminolevulinic acid-4-C ${ }^{14}$ in dogs. J. Lab. Clin. Med. 68: 905.

8. Weber, A. P., and L. Schalm. 1962. Quantitative separation and determination of bilirubin and conjugated bilirubin in human serum. Clin. Chim. Acta. 7: 805.

9. Donato, L., C. M. E. Matthews, B. Nosslin, G. Segre, and F. Vitek. 1966. Applications of tracer theory to protein turnover studies. J. Nucl. Med. 10: 3.

10. Barrett, P. V. D., P. D. Berk, M Menken, and N. I. Berlin. 1968. Bilirubin turnover studies in normal and pathologic states using bilirubin- ${ }^{14} \mathrm{C}$. Ann. Intern. Med. 68: 355 .

11. Berk, P. D., J. R. Bloomer, R. B. Howe, and N. I. Berlin. 1969. Demonstration of defective hepatic bilirubin clearance in Gilbert's syndrome using unconjugated bilirubin- ${ }^{14}$ C. J. Clin. Invest. 48: 7a. (Abstr.)

12. Stein, J. A., J. R. Bloomer, P. D. Berk, and D. P. Tschudy. 1969. Hepatic function in acute intermittent porphyria. J. Clin. Invest. 48: 80a. (Abstr.)

13. Oliverio, V. T., C. Denham, and J. D. Davidson. 1962. Oxygen flask combustion in the determination of $\mathrm{C}^{14}$ and $\mathrm{H}^{3}$ in biological materials. Anal. Biochem. 4: 188.

14. Sterling, K., and S. J. Gray. 1950. Determination of the circulating red cell volume in man by radioactive chromium. J. Clin. Invest. 29: 1614.

15. Read, R. C. 1954. Studies of red cell volume and turnover using radiochromium. Description of a new "closed" method of red cell-volume measurement. $N$. Engl. J. Med. 250: 1021.

16. Berson, S. A., and R. S. Yalow. 1952. The use of $\mathrm{P}^{22}$ or $\mathrm{K}^{42}$ labeled erythrocytes and $\mathrm{I}^{181}$-tagged human serum albumin in simultaneous blood volume determinations. J. Clin. Invest. 31: 572.

17. Chaplin, H., Jr., P. L. Mollison, and H. Vetter. 1953. The body/venous hematocrit ratio: Its constancy over a wide hematocrit range. J. Clin. Invest. 32: 1309.

18. Fairbanks, V. F., and W. N. Tauxe. 1967. Plasma and erythrocyte volumes in obesity, polycythemia, and related conditions. In Compartments, Pools and Spaces in Medical Physiology. P. E. E. Bergner and C. C. Lushbaugh, editors. U. S. Atomic Energy Commission, Oak Ridge. 283.

19. Berman, M., and M. F. Weiss. 1967. Users' Manual for SAAM. U. S. Public Health Service Publication 1703, U. S. Department Health, Education, and Welfare. U. S. Government Printing Office, Washington, D. C.

20. Berman, M., E. Shahn, and M F. Weiss. 1962. The routine fitting of kinetic data to models: a mathematical formalism for digital computer. Biophys. J. 2: 275.

21. Berman, M., M. F. Weiss., and E. Shahn. 1962. Some formal approaches to the analysis of kinetic data in terms of linear compartmental system. Biophys. J. 2: 289. 
22. Berman, M. 1965. Compartmental analysis in kinetics. In Computers in Biomedical Research. R. Stacy and B. Waxman, editors. Academic Press Inc., New York.

23. Nosslin, B. 1964. Mathematical appendices. In Andersen, S. B. Metabolism of human gamma globulin ( $\gamma_{s s}$ globulin). Blackwell Scientific Publications Ltd., Oxford.

24. Berlin, N. I., M. Berman, P. D. Berk, J. M. Phang, and T. A. Waldmann, 1968. The application of multicompartmental analysis to problems of clinical medicine. Ann. Intern. Med. 68: 423.

25. Berman, M. 1963. The formulation and testing of models. Ann. N. Y. Acad. Sci. 108: 182.

26. Berman, M., and R. Schoenfeld. 1956. Invariants in experimental data on linear kinetics and the formulation of models. J. Appl. Physics. 27: 1361.

27. Skinner, S. M., R. E. Clark, N. Baker, and R. A. Shipley. 1959. Complete solution of the three-compartment model in steady state after single injection of radioactive tracer. Amer. J. Physiol. 196: 238.

28. Berman, M., and R. L. Schoenfeld. 1960. A note on unique models in tracer kinetics. Exp. Cell Res. 20: 574.

29. Pettigrew, K. D. 1964. Estimation of a parameter from observations with unequal precisions in the presence of nuisance parameters. PhD. Thesis. George Washington University, Washington, D. C.

30. Engel, R., P. D. Berk, F. L. Rodkey, R. B. Howe, and N. I. Berlin. 1969. Estimation of heme turnover and erythrocyte survival in man from clearance of bilirubin ${ }^{14} \mathrm{C}$ and from carbon monoxide production. Clin. Res. 17: 325. (Abstr.)

31. Coburn, R. F., W. S. Blakemore, and R. E. Forster. 1963. Endogenous carbon monoxide production in man. J. Clin. Invest. 42: 1172.

32. Collison, H. A., F. L. Rodkey, and J. D. O'Neal. 1968. Determination of carbon monoxide in blood by gas chromatography. Clin. Chem. 14: 162.

33. Ostrow, J. D., and R. Schmid. 1963. The protein binding of $\mathrm{C}^{14}$-bilirubin in human and murine serum. J. Clin. Invest. 42: 1286.

34. Bradley, S. E., F. J. Ingelfinger, G. P. Bradley, and J. J. Curry. 1945. The estimation of hepatic blood flow in man. J. Clin. Invest. 24: 890.

35. Caesar, J., S. Shaldon, L. Chiandussi, L. Guevara, and S. Sherlock. 1961. The use of indocyanine green in the measurement of hepatic blood flow and as a test of liver function. Clin. Sci. (London). 21: 43.

36. Hanzon, V. 1952. Liver cell secretion under normal and pathologic conditions studied by fluorescence microscopy on living rats. Acta Physiol. Scand. 28:(Suppl.) 101.

37. Diamond, J. M. 1965. The cooncentrating activity of the gall bladder. In The Biliary System. W. Taylor, editor. Blackwell Scientific Publications Ltd., Oxford. 495.

38. Cohen, S., T. Freeman, and A. S. McFarlane. 1961 Metabolism of ${ }^{131}$ I-labeled human albumin. Clin. Sci. (London). 20: 161.

39. Lutwak, L., and B. T. Burton. 1964. Fecal dye markers in metabolic balance studies. The use of brilliant blue and methylcellulose for the accurate separation of stool periods. Amer. J. Clin. Nutr. 14: 109.

40. Billing, B. H., R. Williams, and T. G. Richards. 1964. Defects in hepatic transport of bilirubin in congenital hyperbilirubinemia: an analysis of plasma bilirubin disappearance curves. Clin. Sci. (London). 27: 245.

41. Araki, Y., T. Miyasaka, T. Kinouchi, M. Kashima, S. Yamamoto, M. Makawa, S. Omori, and H. Ogawa. 1966.
Kinetic studies of bilirubin metabolism: a new approach to the diagnosis of jaundice. Nippon Rinsho. 24: 1002.

42. Araki, V., and M. Kashima. 1968. Mathematical analysis of bilirubin dynamics in man. In Ikterus. K. Beck, editor. Friedrich-Karl Schattauer-Verlag, Stuttgart.

43. Robinson, S. H., C. A. Owen, Jr., E. V. Flock, and R. Schmid. 1965. Bilirubin formation in the liver from non-hemoglobin sources. Experiments with isolated, perfused rat liver. Blood. 26: 823 .

44. Levitt, M., B. A. Schacter, A. Zipursky, and L. G. Israels. 1968. The non-erythropoietic component of early bilirubin. J. Clin. Invest. 47: 1281.

45. Robinson, S. H., R. Lester, J. F. Crigler, Jr., and M. Tsong. 1967. Early-labeled peak of bile pigment in man. N. Engl. J. Med. 277: 1323.

46. Goresky, C. A. 1965. The hepatic uptake and excretion of sulfobromophthalein and bilirubin. Can. Med. Ass. J. 92: 851.

47. With, T. K. 1968. Bile pigments of blood. In Bile Pigments. Academic Press Inc., New York.

48. Berlin, N. I., R. L. Huff, D. C. Van Dyke, and T. G. Hennesy. 1949. The blood volume of the adult rat, as determined by $\mathrm{Fe}^{50}$ and $\mathrm{P}^{22}$ labeled red cells. Proc. Soc. Exp. Biol. Med. 71: 176 .

49. Berlin, N. I. 1964. Life span of the red cell. In The Red Blood Cell: A Comprehensive Treatise. C. Bishop and D. M. Surgenor, editors. Academic Press Inc., New York.

50. Brown, W. R., G. M. Grodsky, and J. V. Carbone. 1964. Intracellular distribution of tritiated bilirubin during hepatic uptake and excretion. Amer. J. Physiol. 207: 1237.

51. Ali, M. A. M., and B. Billing. 1967. Plasma disappearance of conjugated and unconjugated $C^{14}$ bilirubin in the rat with obstructive jaundice. Proc. Soc. Exp. Biol. Med. 124: 339.

52. Bernstein, L. H., J. Ben Ezzer, L. Gartner, and I. M. Arias. 1966. Hepatic intracellular distribution of tritiumlabeled unconjugated and conjugated bilirubin in normal and Gunn rats. J. Clin. Invest. 45: 1194.

53. Grodsky, G. 1967. Studies in the uptake and intrahepatic transport of $\left({ }^{8} \mathrm{H}\right)$-bilirubin. In Bilirubin Metabolism. I. A. D. Bouchier and B. H. Biling, editors. Blackwell Scientific Publications Ltd. 159.

54. Hammaker, L., and R. Schmid. 1967. Interference with bile pigment uptake in the liver by flavaspidic acid Gastroenterology. 53: 31 .

55. Levi, A. J., Z. Gatmaitan, and I. M. Arias. 1968. Two cytoplasmic proteins from rat liver and their role in hepatic uptake of sulfobromophthalein and bilirubin. J. Clin. Invest. 47: 61a. (Abstr.)

56. Berman, M. 1963. A postulate to aid in model building. J. Theor. Biol. 4: 229.

57. Miale, A., Jr. 1964. Measurement of radioiodinated albumin metabolism in man. In Serum Proteins and the Dysproteinemias. F. W. Sunderman and F. W. Sunderman, Jr., editors. J. B. Lippincott Co., Philadelphia. 307.

58. Gill, J. R., Jr., T. A. Waldmann, C. S. Delea, and F. C Bartter. 1969. Abnormal albumin metabolism in "idiopathic edema": Its relationship to sodium metabolism. J. Clin. Invest. 48: No. 6. In press.

59. Eadie, G. S., and I. W. Brown, Jr. 1955. Potential life span and ultimate survival of fresh red blood cells in normal healthy recipients. J. Clin. Invest. 34: 629.

60. Evans, R. L. 1954. Short lived red cells in normal individuals. Nature (London). 173: 129. 
61. Ashby, W. 1921. Transfused blood: periodicity in eliminative activity shown by organism. J. Exp. Med. 34: 127.

62. Berlin, R. 1951. Red cell survival studies in normal and leukemic subjects. Acta Med. Scand. 139(Suppl.) : 252.

63. Callender, S. T. E., E. O. Powell, and L. J. Witts. 1945. Normal red cell survival in men and women. J. Pathol. Bacteriol. 57 : 129.

64. London, I. M., R. West, D. Shemin, and D. Rittenberg. 1950. The origin of bile pigment in normal man. J. Biol. Chem. 184: 351 .
65. Gray, C. H., A. Neuberger, and P. H. A. Sneath. 1950. Studies in congenital porphyria. 2. Incorporation of ${ }^{15} \mathrm{~N}$ in the stercobilin in the normal and in the porphyric. Biochem. J. $47: 87$.

66. Watson, C. J. 1965. The continuing challenge of hemoglobin and bile pigment metabolism. Ann. Intern. Med. 63: 931 .

67. Berk, P. D., D. P. Tschudy, L. A. Shepley, J. G. Waggoner, and N. I. Berlin. Hematologic and biochemical studies in a case of lead poisoning. Amer. J. Med. In press. 